\title{
The Analysis of Pre-service Math Teachers' Level of Understanding the Derivative Concept within the Context of APOS Theory
}

\author{
Selin Urhan ${ }^{1, *}$, and Şenol Dost ${ }^{2}$ \\ ${ }^{1}$ Hacettepe University, Department of Mathematics and Science Education, Ankara, Türkiye \\ ${ }^{2}$ Hacettepe University, Department of Mathematics and Science Education, Ankara, Türkiye
}

\begin{abstract}
APOS (Action-Process-Object-Schema) learning theory is the result of the studies of a mathematics education research group named Research in Undergraduate Mathematics Education Community (RUMEC), whose aim is to examine students' level of comprehending university mathematics subjects. This study aimed to investigate how secondary mathematics education pre-service teachers in a public university structured the geometric dimension of the concept of derivative in their minds in the context of the components of the APOS theory. As data collection tools, questions developed by Çekmez [1] based on the genetic decomposition of Asiala, Dubinsky, Cottrill and Schwingendorf [2] for the geometric dimension of derivatives were used. The study revealed that secondary mathematics education pre-service teachers did not have the mental structures related to this topic and could not learn it at the desired level.
\end{abstract}

Keywords: APOS theory, derivative concept, preservice math teachers.

\section{Introduction}

Among the topics of analysis, the richest concept in terms of geometric and graphical representations is the concept of derivative. Researchers have reported that students have difficulty relating the geometric dimension to the algebraic dimension of the concept of derivative $[1,2]$, and insufficient at analyzing the graphs and understanding the conceptual basis of the slope of the tangent line $[3,4]$. In order for students to comprehend the concept of derivative at the desired level, it is first necessary for them to establish a good level understanding of the geometric dimension of the derivative $[1,5,6]$.

The APOS theory developed based on understanding the concepts in mathematics is a theory Dubinsky put forward drawing on Jean Piaget's theory of reflective abstraction [7, 8]. The APOS theory analyzes the mental structures of an individual when a mathematical concept is being learned. In this way, it is possible to analyze the level of conceptual understanding of students about a concept $[9,10,11]$.

* Corresponding author: $\underline{\text { selin.urhan } @ \text { hacettepe.edu.tr }}$ 
The APOS theory is composed of action, process, object and schema mental structures, and mental mechanisms such as interiorization, encapsulation, de-encapsulation, and thematization. Action is the external transformation of a concept. At this stage, the individual needs to think in each step of transformation and to be guided by an external stimulus. By repeating the actions over time, the individual starts not needing the external stimuli and has internal control over the actions (interiorization). This means that the individual does not have to think about every single step and can skip some steps, which shows that he is in the process stage of understanding a concept [12].

If the individual is aware of the process as a whole, he comprehends that transformations can affect a whole and that transformations can be structured. In this case, the individual encapsulates the process and turns it into a mental object. When a process is encapsulated into an object, it can be de-encapsulated as needed and it would be possible to return to the process. The schema is the structure involving the definitions, organization, and examples of mental structures that an individual builds on mathematical concepts. In the APOS theory, genetic decomposition is a hypothetical model for describing these mental structures and mechanisms that a student may need to learn mathematical concepts [7].

In his doctorate study, Çekmez [1] examined the effect of using dynamic mathematics software on comprehension level of the elementary mathematics pre-service teachers of the geometric dimension of derivative using the APOS theory. Genetic decomposition put forward for the geometric dimension of the derivative concept by Asiala et al. [2], was used to determine the structures students will constitute about the geometric dimension of the derivative concept in their minds.

This study aims to examine how secondary mathematics education pre-service teachers structured the geometric dimension of the concept of derivative in their minds within the framework of the APOS theory.

\section{Method}

This study was carried out with 33 fifth grade students who were studying in the department of secondary mathematics education of a public university during the 20152016 spring term.

Of the questions about the geometric dimension of the derivative concept developed by Çekmez [1] based on the genetic decomposition of Asiala et al. [2], two questions that are appropriate to the mental structures of action, process, and object were used to collect data. The schema is evaluated within the context of the results given to the questions at the level of action, process and object, since it is a mental map involving the definitions and organization of all the mental structures that the individual builds on a mathematical concept.

The questions were applied in a single session in a quiet classroom environment on a day and at a time when all participants could attend. Unlimited time was given to the participants. They were asked to explain their thinking process and the steps they have taken in the documents in which they conveyed the solution process.

The solution processes participants produced for the questions were evaluated according to the rubrics prepared by Çekmez [1] as seen in Table 1 .

Table 1. Coding table

\begin{tabular}{|c|c|c|}
\hline 0 (Incorrect) & 1 (Partially Correct) & 2 (Correct) \\
\hline $\begin{array}{c}\text { Giving the wrong answer } \\
\text { or not answering the } \\
\text { question. }\end{array}$ & $\begin{array}{c}\text { Doing some of the steps the } \\
\text { question requires, or not being } \\
\text { able to reach the exact answer. }\end{array}$ & $\begin{array}{c}\text { Doing the question } \\
\text { correctly. }\end{array}$ \\
\hline
\end{tabular}


In addition to the solution processes, the written discourses of students through which they conveyed their thinking processes were included in the analysis and these discourses were used to clarify the analysis results of the solution processes. Expert opinion was obtained during the analysis of the data and the evaluation of the results.

\section{Findings and discussion}

Of the two questions prepared in accordance with the mental structures of action, process and object, a question providing rich data appropriate to the purpose of study was selected. In this section, findings and results related to this question are presented.

\subsection{Findings regarding the question at the action level}

Figure 1 depicts the question prepared at the level of action to understand the geometric dimension of the derivative.

\footnotetext{
The graph of $y=f(x)$ function was given in the figure.

Order the $f^{\prime}(1), f^{\prime}(2), f^{\prime}(3), f^{\prime}(4), f^{\prime}(5), f^{\prime}(6), f^{\prime}(7)$ values in descending order.
}

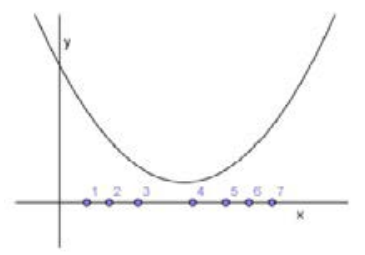

Fig. 1. The question at the level of action

The distribution of the scores students received from this question is given in Table 2.

Table 2. The distribution of scores for the question at the action level

\begin{tabular}{|c|c|c|c|}
\hline & 0 & 1 & 2 \\
\hline Frequency Values & 4 & 6 & 23 \\
\hline Percentage Values & 12 & 18 & 70 \\
\hline
\end{tabular}

Twenty-eight students did not need an algebraic expression of the function; they were able to see the derivative value of a function at a point as the slope of the tangent line plotted on its graph on that point. An example of this situation is given in Figure 2. It is seen that the student solved the question correctly and conveyed his thinking process in accordance with the communication norms in mathematics.

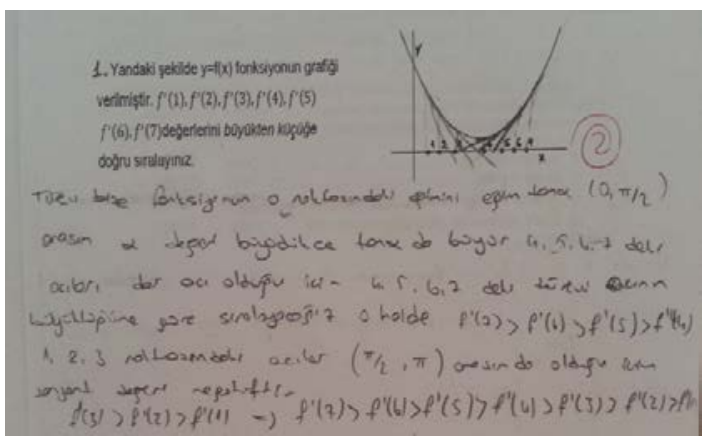

Fig. 2. The solution process of a student for the question at action level 
It was observed that some of the students had some deficiencies in the preliminary knowledge they should have before forming a scheme for the derivative concept. For example, some students had difficulty making a "graphical representation of the line to include the concept of slope". An example of this situation is given in Figure 3.

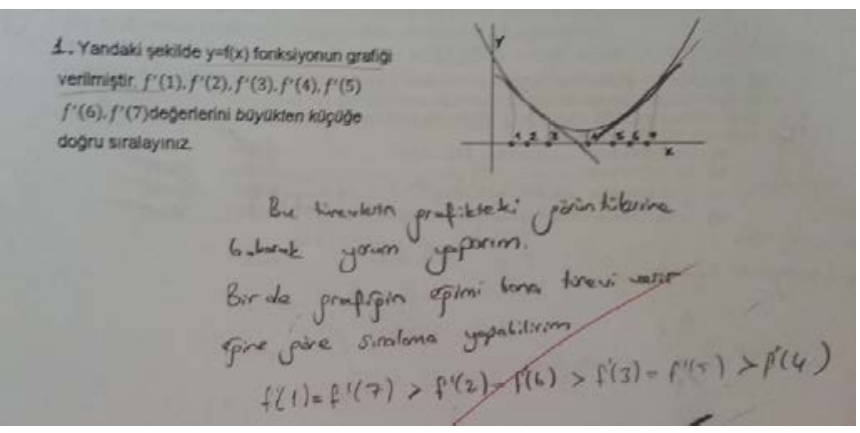

Fig. 3. The solution process of a student for the question at action level

It is seen that the student who uses a mathematically insignificant expression of "The slope of the graph gives me the derivative; I can make an order based on slope" evaluates the derivative value of the function at the given points as an image at those points. The inability of students to form the relation between the derivative value of a function at a point and the slope of the tangent curve drawn on a graph of function at that point was also revealed by Ubuz [13].

\subsection{Findings regarding the question at the process level}

The question prepared at the process level is given in Figure 4 to comprehend the geometric dimension of the derivative.

In the figures, the graphs of the first $y=f^{\prime}(x)$ and second $y=f^{\prime \prime}(x)$ order derivative functions of the function $y=f(x)$ were given. Based on these two graphs, which of the function graphs below represent the $y=f(x)$ function best? Put a tick ( $)$ in the parenthesis ( ) above the graph you choose.

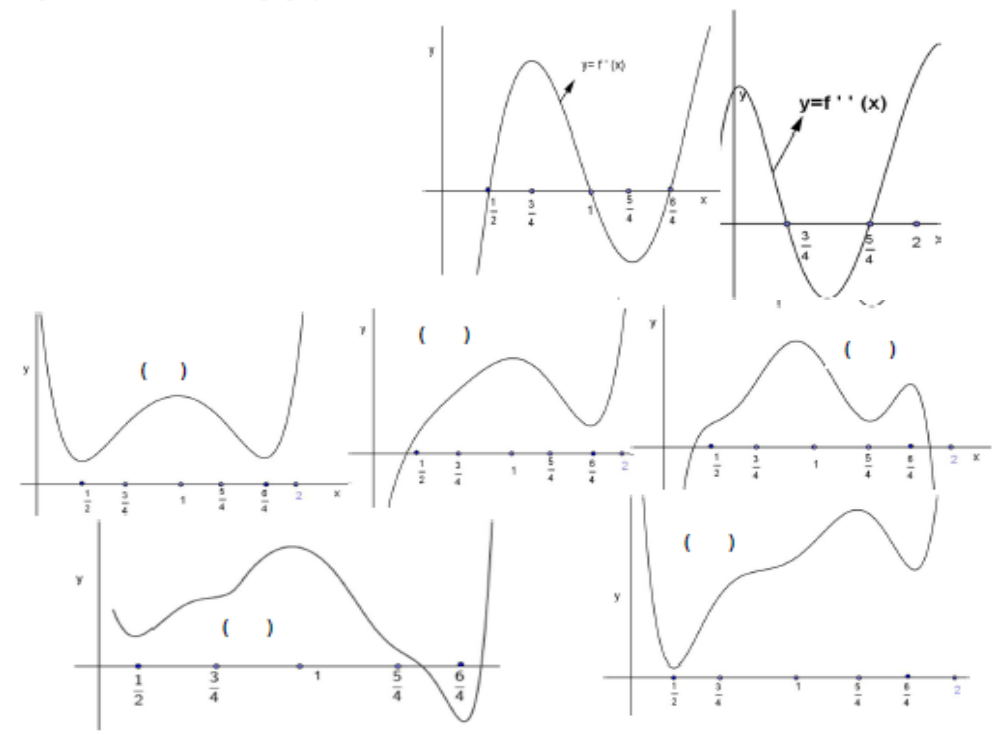

Fig. 4. The question at the process level 
The distribution of the scores students received from this question is given in Table 3.

Table 3. The score distribution for the question at the process level

\begin{tabular}{|c|c|c|c|}
\hline & 0 & 1 & 2 \\
\hline Frequency values & 8 & 0 & 25 \\
\hline Percentage values & 25 & 0 & 75 \\
\hline
\end{tabular}

It was seen that students who answered the question correctly could relate the graph of the first derivative and the second derivative of the function to its own graph. An example of this situation is given in Figure 5.

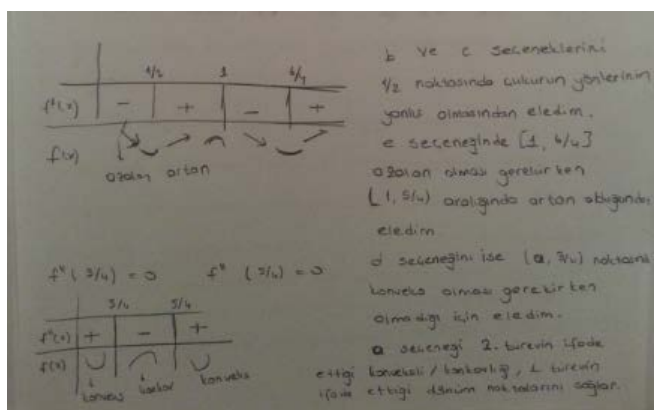

Fig. 5. The solution process of a student for the question at process level

The student who finds out that the function is increasing and decreasing using the points where first derivative graph of the function intersects the $x$-axis and sign diagram also determines the intervals where the function is convex and concave using the points where the second derivative graph intersects the $x$-axis and sign diagram.

It was noted that some students had incomplete knowledge about the relationship between the first and second derivative function of a function and itself. Figure 6 shows an example of this situation.

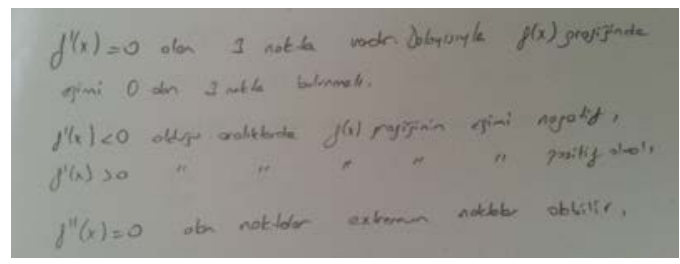

Fig. 6. The solution process of a student for the question at process level

This student only finds the $x$ values that are the zeros of the first derivative and second derivative function of a function and does not make a sign table for derivative functions. This suggests that the student had a lack of knowledge about determining the ranges in which a function is increasing-decreasing and convex-concave. Similar to this finding, Çetin [14] also found that university students could not establish the relationship between a function and the derivation of this function.

Another student went through an invalid solution process as a result of his incorrect knowledge. The solution process of this student is shown in Figure 7. 


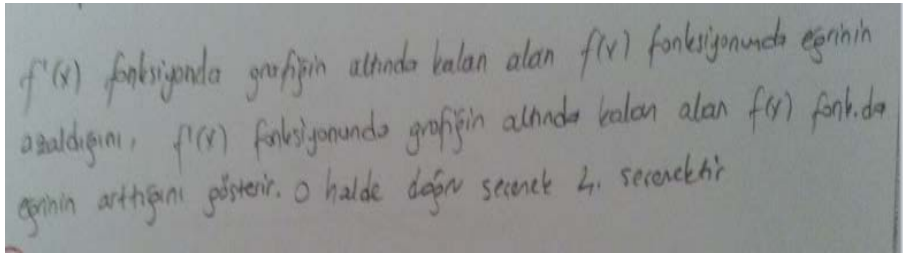

Fig. 7. The solution process of the student

The student's association of the increasing-decreasing state of the function with the area under the graph of the first derivative function indicates that he had incorrect knowledge. The expressions written by the student with incorrect and incomplete knowledge are invalid.

\subsection{Findings regarding the question at the object level}

Figure 8 depicts the question prepared at the object level to comprehend the geometric dimension of the derivative.

\footnotetext{
It is known that $y=f(x)$ is a function and $\lim _{x \rightarrow 1} \frac{f(x)-f(1)}{x-1}=3$. When $\varepsilon=\frac{1}{2}$ within the definition of limit, what is the biggest $\delta$ value that corresponds to this $\varepsilon$ variable?

Which of the following is the statement above equivalent to? Put a tick $(\sqrt{ })$ next to the item or items you believe is/are equivalent.
}

i) How far the variable $x$ could be to the value 1 so that the distance of the slope of the line passing through the $(x, f(x))$ and $(1, f(1))$ points to value 3 is smaller than $1 / 2$.

ii) How far the variable $x$ could be to the value 3 so that the distance of the slope of the line passing through the $(x, f(3))$ and $(x, f(1))$ points to value 1 is bigger than $1 / 2$.

iii) How close the variable $x$ could be to the value 1 so that the distance of the slope of the line passing through the $(1, f(3))$ and $(x, f(3))$ points to 3 is smaller than $1 / 2$.

iv) How close the variable $x$ could be to the value 3 so that the distance of the slope of the line passing through the $(x, f(x))$ and $(x, f(1))$ points to 1 is minimum $1 / 2$.

Fig. 8. The question at the object level

The distribution of the scores received by students for this question is given in Table 4 .

Table 4. The distribution of scores for the question at the object level

\begin{tabular}{|c|c|c|c|}
\hline & 0 & 1 & 2 \\
\hline Frequency values & 7 & 5 & 21 \\
\hline Percentage values & 21 & 15 & 64 \\
\hline
\end{tabular}

It was observed that students who gave the correct response generally made a drawing or used the formal definition of the limit. Figure 9 shows the solution process of a student who answered the question correctly using the formal definition of the limit.

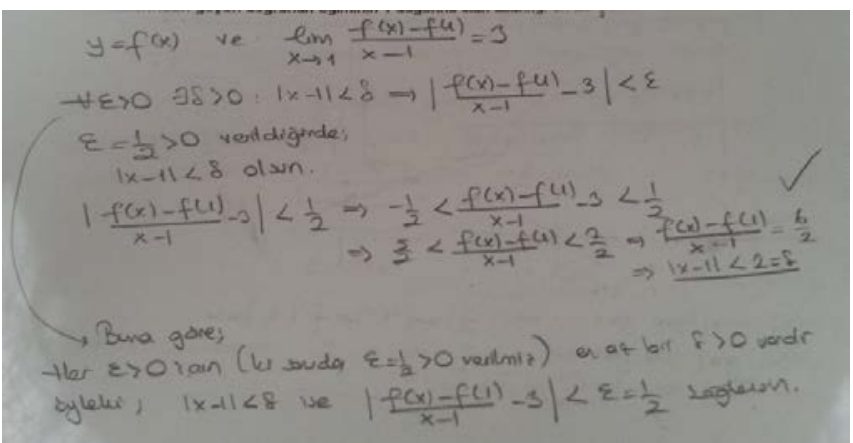

Fig, 9. The solution process of the student 
As seen in Figure 9, the students who answered the question correctly mostly provided a detailed explanation and used the symbolic language of the mathematics correctly and carefully.

Some students chose the expression given in (iii) as the equivalent of the expression given in the question, indicating that these students had difficulty making "the graphical interpretation of the ordered pair $(x, y)$ when $y$ is defined by $f(x)$ ". This suggests that some students lack the preliminary knowledge about the concept of the derivative.

On the other hand, some students seem to have thought that the use of the word "far" is wrong in the explanations regarding the concept of limit. Figure 10 exemplifies this situation.

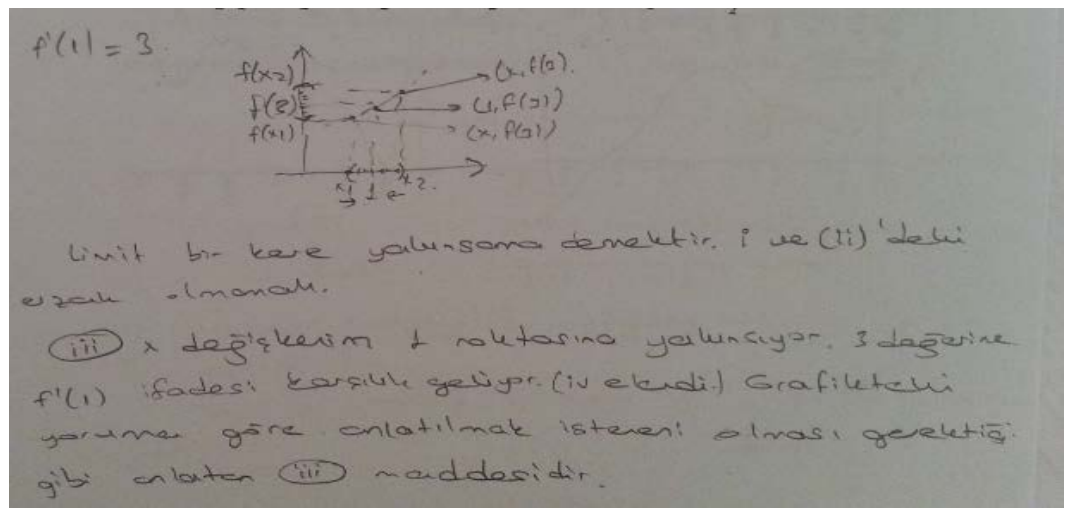

Fig. 10. The solution process of the student.

It is understood from the statements of the student that he reaches the conclusion that the word "far" should not be used in the definition of the limit concept. It is seen that the student could not understand the formal definition of limit, and thus eliminated the correct answer. This result coincides with the findings of Barak's [15] study conducted to reveal the misconceptions of pre-service teachers regarding the limit concept.

\section{Conclusions and suggestions}

This study investigated how secondary mathematics education pre-service teachers structure the geometric dimension of the concept of derivative in their minds within the framework of the APOS theory. The results show that the pre-service teachers have some deficiencies in their preliminary knowledge or incorrect knowledge about this topic. This means that the pre-service teachers do not have the mental structures about this topic and could not learn the topic at the desired level, and thus the derivative scheme they have did not develop adequately. This situation should be taken into consideration by the instructors and the teaching environments for the concept of the derivative should be arranged in this context; and measures aiming at eliminating the deficiencies of students should be taken.

On the graphs of one variable functions, either a tangent line cannot be drawn or if and only if one can be drawn at a point. However, as Çekmez [1] maintained, more than one tangent can be drawn at one point on the graphs of parametric functions. In this context, it would also be useful to conduct research that explores students' understanding level of parametric functions.

A study can be conducted with secondary school students on their level of understanding the concept of derivative. Within the framework of the results of this study, learning environments should be arranged in a way to reduce the difficulties experienced by students. 


\section{References}

1. E. Çekmez, Dinamik matematik yazılımı kullanımının öğrencilerin türev kavramının geometrik boyutuna ilişkin anlamalarına etkisi. Doktora tezi. Karadeniz Teknik Üniversitesi, Eğitim Bilimleri Enstitüsü (2013).

2. M. Asiala, E. Dubinsky, J. Cottrill, E. K. Schwingendorf, Journal of Mathematical Behavior, 16, 4 399-431. (1997).

3. I. Biza, Is the Tangent Line Tangible? Students' Intuitive Ideas About Tangent Lines, 6-11. (2007).

4. J. Isaacson, The effects of static graphic, animated graphic, and interactive animated graphic presentations on acquisition of the tangent concept. Unpublished doctoral dissertation. University of Florida. (1999).

5. M. Artigue, Analysis, 167-198. (1991).

6. B. Hartter, Concept image and concept definition for the topic of derivative. Unpublished doctoral dissertation. Illinois State University. (1995).

7. E. Dubinsky, Reflective abstraction in advanced mathematical thinking, 95-123. (1991).

8. E. Dubinsky, Towards a theory of learning advanced mathematical concepts, 121-123. (2000).

9. I. Arnon, J. Cottrill, E. Dubinsky, A. Oktaç, S. Roa Fuentes, M. Trigueros, K. Weller, APOS theory: A framework for research and curriculum development in mathematics education. (2014).

10. E. Dubinsky, G. Harel, The nature of the process conception of function, 85-106. (1992).

11. Ö. Şefik, Öğrencilerin iki değişkenli fonksiyon kavramını anlamalarının APOS teorisi ile analizi. Yüksek lisans tezi. Hacettepe Üniversitesi, Eğitim Bilimleri Enstitüsü. (2017).

12. E. Dubinsky, K. Weller, M. McDonald, A. Brown, Educational Studies in Mathematics, 58 335-359. (2005).

13. B. Ubuz, International Journal of Mathematical Education in Science and Technology, 38, 5 609-637. (2007).

14. İ. Çetin, Students' understandig of limit concept: An APOS perspective. Doctoral dissertation. Orta Doğu Teknik Üniversitesi, Fen Bilimleri Enstitüsü. (2009).

15. B. Barak, Limit konusundaki kavram yanılgllarının belirlenmesi. Yüksek lisans tezi. Balıkesir Üniversitesi. (2007). 